América sin Nombre, n. ${ }^{\circ} 21$ (2016): 73-87

DOI: 10.14198/AMESN.2016.21.05

ISSN: 1577.3442 / eISSN: 1989-9831

Fecha de recepción: 26/10/2016

Fecha de aceptación: 10/11/2016
Puede citar este artículo como:

Hernández Reyes, Dalia. «Las posibilidades de la loa novohispana dieciochesca a través de la Relación peregrina del agua». Teatro breve virreinal. Miguel Zugasti (coordinador). América sin Nombre, 21 (2016): 73-87, DOI: 10.14198/AMESN.2016.21.05

Link para este artículo: http://dx.doi.org/10.14198/AMESN.2016.21.05

\title{
Las posibilidades de la loa novohispana dieciochesca a través de la Relación peregrina del agua
}

\author{
The possibilities of the eighteenth century Novohispanic loa through the Relación \\ peregrina del agua
}

\author{
Dalia Hernández Reyes* \\ Seminario de Cultura Literaria Novohispana \\ Instituto de Investigaciones Bibliográficas, UNAM
}

\section{Resumen}

Este artículo estudia un conjunto de seis loas representadas en carros triunfales como parte de la fiesta llevada a cabo en Querétaro en 1738, con motivo de la inauguración de su acueducto. Aunque la historiografía y la crítica de la literatura novohispana no suelen considerar este tipo de textos, se pretende demostrar que las loas escritas para carro triunfal constituyen una de las modalidades del género dramático breve loa, cercano por sus características formales y escénicas a la loa cortesana, pero con una marcada función ecfrástico-explicativa del aparato efímero que le sirve al mismo tiempo de referente alegórico y de marco físico de representación. Por otra parte, por la notable presencia de la música, el canto y el estilo recitativo, representan una muestra del proceso de musicalización al modo italiano de este género en la praxis novohispana.

Palabras clave: Loa para carro triunfal. Nueva España. Siglo xviII. Géneros dramáticos breves. Arquitectura efímera. Ecfrasis. Emblemática. Influencia musical italiana.

\begin{abstract}
This article consists in the analysis of six loas represented in triumphal carts as part of the inaugural celebrations of the aqueduct in Querétaro in 1738. Although the historiography and the Novohispanic literature critic do not consider this type of documents, this study aims to demonstrate that the loa elaborated for triumphal carts correspond to one of the categories of the short dramatic genre of the loa, which is close to the representations done for the court for its formal characteristics, but with a distinctive ekphrasis-explanatory function of the ephemeral apparatus that is at the same time
\end{abstract}

* Dalia Hernández Reyes es académica del Instituto de Investigaciones Bibliográficas de la UNAM, adscrita al Seminario de Cultura Literaria Novohispana del citado Instituto. Asimismo, es profesora de literatura novohispana en la Facultad de Filosofía y Letras de la UNAM. Ha presentado y publicado en diversos foros académicos nacionales e internacionales trabajos sobre el teatro novohispano, las relaciones entre teatro y fiesta, la escenografía y la puesta en escena, la censura teatral, la recepción del teatro español barroco y de la preceptiva teatral neoclásica en el siglo XviII novohispano. Actualmente tiene en prensa el libro De corte y colegio: la "Comedia de San Francisco de Borja» y el teatro jesuita novohispano del siglo XVII (UNAM). En marzo de 2016 recibió el reconocimiento Sor Juana Inés de la Cruz (UNAM) por su trayectoria académica. 
an allegoric referent as well as a physical representation frame. Besides, by the notable presence of music, chants and the recitative style, it represents an example as that of an Italian musicality process in the Novohispanic praxis.

Keywords: Loa for triumphal cart. New Spain. Eighteenth century. Short dramatic genres. Ephemeral architecture. Ekphrasis. Emblems. Italian musical influence.

La fundación y dedicación de dichas obras arquitectónicas daría lugar a diversas celebraciones, de las En 1680, Carlos de Sigüenza y Góngora cantaba las Glorias de Querétaro en ocasión de la dedicación de la iglesia de la Congregación de la Virgen de Guadalupe, y en el primer capítulo, en apretada síntesis, explicaba «algunas de las grandezas de las materiales y formales con que se ennoblece Querétaro» $(1)^{1}$, en virtud de las cuales bien se justificaba el lugar preeminente que la provincia y ciudad de Querétaro habían alcanzado hacia finales del siglo XVII. Ciertamente, la ciudad era considerada ya la tercera en importancia de la Nueva Espańa, por su productiva economía sustentada en la ganadería, la agricultura, el comercio y los obrajes textiles; además, por su estratégica ubicación geográfica, era la entrada y camino obligado -el llamado camino de tierra adentro- hacia el territorio del norte, de la zona minera y de las misiones tanto de colonización como de evangelización (Super 1986, García Ugarte 94-100). La riqueza de la provincia se veía reflejada particularmente en las construcciones de carácter religioso de su ciudad, Santiago de Querétaro, pero sin duda será a lo largo del siglo xvirI cuando la ciudad adquiera su característica fisonomía con notables y costosas edificaciones de señoriales casonas y de nuevos templos y conventos, así como de numerosas remodelaciones de los ya existentes ${ }^{2}$.

1. Regularizo la ortografía y la puntuación, aunque respeto las vacilaciones vocálicas, de todas las citas de textos antiguos.

2. En las segundas Glorias de Querétaro de 1803, Zelaá apuntaba: "No es de menor lustre para la ciudad de Querétaro la magnificencia y esplendor que se emplea en el culto divino: omito el referirlo por ser tan notorias sus fiestas anuales, sus procesiones penitentes, sus cofradías devotas, sus capellanías perpetuas y memorias piadosas. Siete eran las iglesias con que se adornaba esta hermosísima ciudad cuando se fabricó la de nuestra Congregación [de Guadalupe]; mas en el día pasan ya de catorce las que tiene» (32-33). Entre las construcciones más notables, construidas o remozadas entre 1680 y 1750 , se cuentan: el Colegio de Propaganda Fide, los colegios e iglesia de la Compañía de Jesús, los conventos e iglesias de San Francisco, de Santo Domingo, de San Agustín, los femeninos del Carmen, de San José de Gracia, los beaterios de Santa Rosa de Viterbo y el de San José, así como el Hospicio cuales quedó el indicio de algún sermón impreso ${ }^{3}$. Sin embargo, de todas estas fiestas, ninguna alcanzó el realce y trascendencia de las que se llevaron a cabo durante quince días en Santiago de Querétaro en 1738 con motivo de la culminación de los trabajos para la construcción del acueducto que permitió la introducción de agua potable a la ciudad, gracias a la generosidad de Juan Antonio de Urrutia y Arana, marqués de la Villa del Villar del Águila, promotor y costeador de dicha obra. Las motivaciones de la construcción hidráulica oscilan entre la realidad y la leyenda, que implica un amor verdadero y casto pero imposible entre el marqués y sor Marcela, una monja capuchina, quien al parecer era además su sobrina política ${ }^{4}$. No obstante, la historia oficial

de la Merced. Este mismo autor ofrece un pormenorizado recuento de las diversas etapas constructivas de los edificios religiosos desde la fundación de la ciudad y hasta 1803, año en que publica su obra (33-72). Puede consultarse también Ramírez Montes (1997), quien edita un informe presentado por el regidor de Querétaro Esteban Gómez Acosta acerca del estado que guardaba la provincia y la ciudad hacia 1743 .

3. A manera de ejemplo, véanse: Sermón que en el día primero de su celebridad, en la muy plausible fiesta de la ampliación del crucero y reedificación del Templo de la milagrosa santísima cruz de piedra de la ciudad de Querétaro, predicó... Josef de Castro, predicador apostólico en el Colegio de la Santa Cruz de dicha ciudad... México: Herederos de la Viuda de Francisco Rodríguez Lupercio, 1702 (Medina, III, 333); Exaltación gloriosa del más pequeño, sermón panegírico de... San Francisco, discurrido y predicado por... Juan de Estrada... con las circunstancias de la dedicación del nuevo mayor retablo de su iglesia... México: Josef Bernardo de Hogal, 1730 (Medina, IV, 287288); Sermón panegírico en la solemne, plausible dedicación del nuevo admirable retablo que... en la iglesia de... San Francisco de la ciudad de Querétaro ... [predicó] el día 13 de junio de este año de 1732... Juan de Montañés... México: Josef Bernardo de Hogal (Medina, IV, 349).

4. Entre el grupo de monjas que fundaría el Convento de San José de Gracia en Santiago de Querétaro (que por cierto fueron encomendadas a los marqueses en su viaje de la Ciudad de México a Querétaro), se contaban dos jóvenes que ingresarían como novicias; una de ellas era Francisca de Moctezuma y Guerrero, sobrina de la marquesa del Villar del Águila, doña 
atribuye la acción del marqués a su generosidad y caridad $^{5}$ :

Pretende la ciudad de Querétaro, como agradecida, que sepan todos lo que su ilustrísimo bienhechor, el señor don Juan Antonio de Urrutia y Arana, caballero del Orden de Alcántara y marqués de la Villa del Villar de el Águila, ha hecho por ella en la introducción del agua, y lo que la mesma ciudad ha ejecutado en las fiestas que acaba de hacer en agradecimiento de tan peregrino beneficio. El señor marqués hace, pero no dice; ésta es máxima de hombres grandes, porque quien es para poco dice mucho, y quien hace mucho habla poco. Por eso esta ciudad, ya que el señor marqués hace, pero no dice, pretende, como agradecida, que sepan todos lo que calla quien tanto ha hecho; que si al bienhechor toca ocultar el beneficio, al que le recibe pertenece publicarlo por muestra de su agradecimiento (Navarrete 1-2) .

La celebración tuvo lugar desde el 17 de octubre y hasta el 1 de noviembre de 1738, e incluyó, además de la consabida misa, la bendición de todas las cajas y pilas de agua desde las cuales se distribuía el líquido a la ciudad, artificios de pirotecnia, corridas de toros, peleas de gallos y de perros, baile de la maroma (juegos de malabares) y palo encebado, un paseo de indios y un desfile de carros triunfales -repartido en cinco días- con la representación de sus respectivas loas, así como cuatro comedias -también con sus loas- escenificadas en un teatro efímero creado especialmente para la ocasión ${ }^{7}$.

María Josefa Paula Guerrero Dávila Moctezuma. A esta joven se atribuye en la mayor parte de las versiones de la leyenda el nombre religioso de sor Marcela, quien como prueba de amor pidió al marqués que llevará agua a su convento.

5. Cabe señalar que si bien es cierto que Juan Antonio de Urrutia realizó la obra como un empeño personal, también se trató de una encomienda de carácter oficial, pues «el marqués participó activamente en el seguimiento de los trabajos, ejerciendo como superintendente de las obras 'en virtud de un despacho superior del excelentísimo señor marqués de Casafuerte', virrey de Nueva Espańa» (Gordo Peláez 624).

6. Todas las citas proceden de la primera edición de 1739.

7. Las comedias que se pusieron en escena por una compañía profesional de cómicos se repartieron en las tardes de cuatro días, y aunque el relator calla los nombres de los autores son fácilmente identificables. La primera, El conde Partinuplés de Ana María Caro, tuvo lugar el 19 de octubre; Las armas de la hermosura de Pedro Calderón de la Barca, el sábado 25; Darlo todo y no dar nada también de Calderón, el día 26, y finalmente El robo de Helena atribuida a Cristóbal Monroy
El relato de la fiesta estuvo a cargo del jesuita Francisco Antonio Navarrete ${ }^{8}$ y se imprimió con el título de:

Relación peregrina de la agua corriente que para beber y vivir goza la muy noble, leal y florida ciudad de Santiago de Querétaro. Compuesta por el muy reverendo padre maestro Francisco Antonio Navarrete, profeso de la sagrada Compañia de Jesús. Describense las plausibles fiestas que dicha nobilísima ciudad, como agradecida, hizo al ver logrado tan peregrino y perenne beneficio. Y dedica este cristalino monumento de su gratitud a la ilustre señora doña María Paula Guerrero Dávila, marquesa de la Villa del Villar del Águila. Impresa en México con licencia, por Josef Bernardo

y Silva, el martes 28 (Urzáiz Tortajada, I, 181, 184, 227; II, 458). Quizá por ser un hecho inusitado, la relación ofrece una prolija descripción del teatro efímero erigido en la Plaza Mayor de Querétaro: «Y porque lo pomposo de las fiestas, el decoro de una tan noble ciudad y el concurso de tan ilustres y discretos oyentes pedían que no se representase a cielo raso, porque el sol y el aire encenderían el desabrimiento para la mormuración, tenían prevenido los tres comisarios, ya nombrados en esta relación, un hermoso y capaz coliseo con aquel esmero y primor que supo idear la arte y el buen gusto, para que los oyentes defendidos de aire y del sol lograsen una divertida comodidad. El teatro o fachada principal del coliseo se componía de bastidores y bofetones, tan bien pintados, que su vistosa variedad salió al temple de los corazones, llenos de gusto al ver en Querétaro tan bien fingido un teatro, que pudiera dar celos a los mayores que veneró la Antigüedad y que hoy lucen en las cortes de Europa con asombro de la arte y de la magnificencia. A los dos lados, de donde como de repisas arrancaba un majestuoso arco que hacía resaltar con mayor belleza lo primoroso del teatro, se veían, al lado derecho, pintadas las armas reales y, al izquierdo, las de esta nobilísima ciudad, y como haciendo guarda a unas armas, que ellas por sí causan respecto, miedo y veneración, se dejaban ver dos alabarderos, tan bien imitados, que aunque por lo común son desalmados, tenían mil almas por la singular viveza del pincel» (Navarrete 121-122). En el centro del arco de la embocadura del escenario, se "pintó un majestuoso carro triunfal y en él, triunfando de esta América, nuestro católico monarca Felipe V, con tanta belleza y majestad, que los cuatros caballos del carro del sol, que lo tiraban, no quisieron después subir al cielo» (122).

8. «Navarrete (P. Francisco Antonio). -Nació en la ciudad de Baeza a 21 de Octubre de 1684, y habiendo pasado joven a la N. E., profesó en el instituto de S. Ignacio en Topozotlán [sic] de México a 31 de Julio de 1710. Falleció en el Colegio de Querétaro año de 1749'. - Beristáin» (citado por Medina, IV, 486). 
de Hogal, ministro e impresor del Real y Apostólico Tribunal de la Santa Cruzada. Año de $1739^{9}$.

Casi la mitad del texto se destina a la narración festiva, la descripción de los carros triunfales y los textos de las loas, a cuyo estudio están dedicadas estas páginas. Comprende además como parte de los preliminares literarios varias composiciones poéticas (sonetos, romances, décimas y una carta latina).

Dada la importancia que esta obra hidráulica tuvo para la ciudad y su actual valor histórico, el impreso no es desconocido, y de hecho cuenta con cinco ediciones modernas: la primera de $1944^{10} \mathrm{y}$ la última de 2013, que se anuncia como edición revisada, actualizada y anotada. No obstante, en las escuetas notas, introducciones o presentaciones que preceden al texto, poco o nada se menciona acerca de los textos dramáticos que acompañan la relación. Sólo Francisco Monterde -experto conocedor de las fuentes documentales para la historia del teatro novohispano- hace un breve llamado de atención acerca de este testimonio en su "Preámbulo» a la edición de Bibliófilos Mexicanos: «otros indicios del reposado vivir están en las muestras de poesía dramática; en esos embriones de teatro -sembrados de reminiscencias mitológicas- que se deben relacionar con las moralidades, por las entelequias [...] Para quienes sigan la evolución del teatro serán útiles, además, los informes que proporciona, con los títulos de las comedias [y] la mención de diversas loas» $(10)^{11}$. Varias décadas después de este crítico, Ortiz realizó un interesante acercamiento a la Relación peregrina, algunos aspectos de la fiesta y de las loas $(105-117)^{12}$.

El impreso ha sido también registrado en los principales repertorios bibliográficos, como en la Bibliografía mexicana del siglo XVIII, de Nicolás León, quien describe la portada, menciona los preliminares legales y literarios (372, núm. 893), pero de las loas no ofrece información. Por su parte, José

9. Cito por el ejemplar resguardado en el Fondo Reservado de la Biblioteca Nacional de México, clasificación: RSM 1739 M4NAV.

10. No he podido revisar ningún ejemplar de esta edición, pero la cita Ayala (178, núm. 701 bis).

11. Aunque seguramente Monterde no conoció la Relación peregrina antes de 1961, pues no la cita en su Bibliografía del teatro en México de 1933.

12. Moreno Pérez menciona la celebración por la puesta en marcha del acueducto, y en particular llama su atención el teatro efímero construido para la representación de las comedias (47-49), pero no menciona ni un detalle de las loas también escenificadas con tal motivo.
Toribio Medina -en el tomo IV de La imprenta en México- consigna el volumen, y en su descripción añade: «en las pp. 81-89 hay una loa en verso del Gremio de los Indios» y «otra loa en las pp. 144$149 »(486)^{13}$.

Ciertamente, en las páginas indicadas se encuentran unas loas, pues el teatro -ya en los géneros dramáticos breves, ya en los extensos- resultaba consustancial a la fiesta novohispana, aunque pocas veces se recogían los textos en la correspondiente relación. Sin embargo, tal parece que el bibliógrafo chileno no prestó la atención acostumbrada a este libro, pues la Relación peregrina incorpora no dos sino seis loas; por otra parte, la que considera primera constituye en realidad el texto de dos loas. Aunque en defensa de este bibliógrafo, hay que señalar que los textos de las loas - a golpe de vista- no siempre son fácilmente distinguibles del cuerpo principal de la Relación peregrina, pues no todas se encabezan con el paratexto correspondiente, esto es, con el titulillo que indique su adscripción genérica o, por lo menos, que se trata de un texto independiente.

\section{III}

La elaboración y costo de los carros triunfales estuvieron a cargo de los gremios ${ }^{14}$ de la ciudad, no así el diseño de su programa alegórico -que conjunta en algunos casos lo popular y lo culto- y la composición de las loas, en los cuales se evidencia la participación de autores con una más cuidada formación intelectual. En este aspecto de la autoría, Monterde considera que varias de las loas proceden de la mano del jesuita Navarrete. Sin embargo, no habiendo más testimonios de la labor poética del jesuita que el romance jocoserio que inaugura los preliminares literarios de la Relación peregrina, no es posible establecer de modo determinante este tipo de filiaciones. Aunque no hay que pasar por alto que el padre Francisco Antonio Navarrete estaría familiarizado con los diversos géneros del teatro, pues

13. La Relación peregrina... también ha sido consignada por Ayala (176, núm. 701).

14. Por gremio debe entenderse, en este contexto, no sólo la «corporación formada por los maestros, oficiales y aprendices de una misma profesión u oficio, regida por ordenanzas o estatutos especiales», sino también en su acepción de «conjunto de personas que tienen un mismo [...] estado social» (DRAE). Sólo así puede entenderse la consideración de la población indígena de la zona como gremio de los indios. 
era una práctica común en los colegios jesuitas, y quizá en algún momento él mismo haya promovido u organizado alguna función teatral en su desempeño como rector del Colegio de San Ignacio de Querétaro (1733-1735, y al parecer también en 1739).

El desfile se organizó en torno a cinco carros acompañados de diversas cuadrillas acordes al tema simbólico de cada una de tales arquitecturas efímeras móviles, más un denominado paseo de los indios. Cada uno de estos carros -en distintos días- siguió un trayecto previamente establecido por las calles de la ciudad, cuyas principales estaciones o paradas fueron las Casas Reales en la plaza principal y la casa del marqués de la Villa del Villar del Águila, aledaña al convento de las capuchinas ${ }^{15}$. En cada uno de estos sitios se detenía la comitiva y sobre el espacio físico del mismo carro triunfal -a modo de tablado móvilse escenificaba la correspondiente loa, a excepción de la loa de los indios, cuya representación fue a ras de suelo.

Desde el punto de vista formal, el contexto, las estrategias de elaboración, los recursos poéticos y las características de representación, estas seis loas se vinculan a las denominadas -en la pionera clasificación de Cotalero y Mori- loas de casas o fiestas particulares, aquellas que se hacían para acompañar las comedias en honor de renombrados señores o familias, "con música o sin ella, con ocasión de bodas y bautizos, promoción de destinos, cumpleaños y fiestas onomásticas y hasta en las profesiones religiosas» (XLI), y de cualquier otra situación digna de conmemorarse. Por estos mismos rasgos, el propio Cotarelo consiente en que "casi adquieren el valor" $y$, por tanto, análoga caracterización de las loas cortesanas o de fiestas reales. De hecho, en su aproximación al género,

15. Como curiosidad, merece indicarse el hecho de que el marqués, luego de su llegada a Querétaro, mandó construir una casa -distinta de la conyugal- junto al Convento de San José Gracia, pues «atraído del divino hechizo de las religiosas capuchinas, que acababan de hacer del todo feliz a esta ciudad, dejó su cristiano y piadoso genio las asistencias de su casa y de su ilustre esposa, por gozar de más cerca las delicias espirituales que enciende en las almas devotas su santa y siempre provechosa conversación. Y para que de más cerca le calentase el fuego de tan santa comunidad, labró una casa junto al convento, que por lo magnífico y costoso de su obra [...] dio a entender al mundo [...] el amor que a las reverendas madres capuchinas tenía» (Navarrete 30). El episodio por supuesto ha abonado a la leyenda tejida alrededor de Juan Antonio de Urrutia y sor Marcela, pues se ha interpretado como uno más de los indicios del supuesto amor entre ellos.
Spang enfatiza que debe "figurar igualmente en este lugar -es decir, dentro de la modalidad cortesana- la loa para casas particulares [...] dado que la diferencia entre la loa palaciega y la de casas particulares es más bien de cantidad y no de calidad, es decir, tanto el contenido como la forma y la escenificación guardan las mismas características básicas que la loa palaciega, sólo que se adaptan a las posibilidades técnicas y pecuniarias del particular que las encargaba» (18).

A pesar de su abundancia en el panorama textual novohispano ${ }^{16}$, las loas no han recibido suficiente atención crítica, y, más aún, las loas para carro triunfal y sus congéneres, las loas para arco triunfal, no suelen considerarse como parte del género dramático ${ }^{17}$. Quizá una de las principales razones para este olvido radique en que no necesariamente se anuncian como loas; los principales paratextos -títulos- con los cuales se introducen y encabezan son explicación y descripción o romance y canción, que remiten, por una parte, a una de sus funciones en relación con la arquitectura efímera, y, por otra, a las formas poéticas en las cuales se expresan, aunque también se emplea el término $l o a^{18}$.

16. A pesar de que la mayor parte del repertorio dramático representado en Nueva España era de procedencia peninsular, los dramaturgos locales tuvieron oportunidad de ensayar en los géneros breves que complementaban la puesta en escena, y particularmente en el de la loa. Basta revisar los considerables ejemplos que proporciona Monterde en su Bibliografía del teatro y los corpora editados del carmelita Juan de la Anunciación (1985; García Gómez) o de Cayetano Javier de Cabrera y Quintero (1976).

17. Si bien contamos con algunos avances (Pasquariello, Maldonado, García Gómez), no existe hasta el momento un estudio integral del desarrollo de la loa y sus diversas modalidades en la Nueva España. Aunque parece que el tipo de loas que aquí se trata comienza a suscitar algún interés. En un reciente artículo, Zugasti (2014) estudia y edita una loa de arco triunfal en honor del virrey conde de la Monclova en su paso por la ciudad de Puebla en Nueva Espańa, y ya con anterioridad (2008) había centrado su atención en una loa de arco y en otra de carro triunfal representadas en 1716 en la villa del Potosí en el virreinato de la Nueva Castilla, con motivo de la llegada del virrey Diego Morcillo.

18. Es de resaltar que para el siglo XviII novohispano hay algunos textos que agregan a los títulos de loas de arco, tal vez para enfatizar su carácter dramático y su primigenia función laudatoria, los términos de representación panegírica. Es el caso, por ejemplo, del Métrico indicio y representación panegírica del triunfal arco que al recibimiento y feliz ingreso del Excmo. Sr. D. Pedro Cebrián y Augustín, Conde de Fuenclara..., le erigió su capital, nobilísima imperial Ciudad de México. Año de 1740, o de la Representación panegírica y métrica 
Sin embargo, si se analizan detenidamente, se podrá advertir que mantienen desde el nivel supragenérico, es decir, un primer nivel en el cual opera -en palabras de Spang- "una sistematización de los rasgos que encontramos en todo tipo de loa y a partir del cual se pueden rastrear las variantes y diversificaciones» (9), los elementos básicos para ser adscritas al género dramático loa. En efecto, como rasgos caracterizadores esenciales se pueden enunciar: su finalidad laudatoria (ya sea de personas, de lugares o de la situación específica que la propicia), su brevedad (que las reduce a un solo acto), generalmente representada por un solo personaje y por ende monologada, mínima intriga y en consecuencia escasa dramaticidad.

Comparten con la especie cortesana y particular un lenguaje más sofisticado que se funda en la tópica panegírica cuyos paradigmas fundamentales pueden ser astrológico, mitológico, búblico e histórico; sus recursos escenotécnicos suelen ser más elaborados y casi siempre constituyen un valor o sentido alegórico; asimismo se encuentran diversos ejemplos con música y canto, no sólo como acompañamiento sino como elementos integrados al discurso verbal, siguiendo la tendencia que desde mediados del siglo XVII podía observarse en la loa cortesana y en la sacramental.

Por otra parte, hay que mencionar dos rasgos que alejan -desde el punto de vista supragenéricolas loas de carro de otras modalidades, incluyendo las cortesanas y particulares, con las cuales guardan más semejanza. En primer lugar, su independencia funcional: se trata de piezas dramáticas autónomas que no anteceden ni guardan relación con una obra mayor. Ya Méndez Plancarte, al abocarse a las loas de Sor Juana, recordaba que «la loa recibe plena autonomía, no sólo como pieza separada de la mayor, sino como dotada de asunto propio y distinto» (LII); por ello mismo en su edición de la obra sorjuanina, designa a las loas que no acompañan una comedia o auto sacramental como "loas sueltas», ya sean de tema religioso o profano. En este mismo sentido, ha apuntado Zugasti que «no todas las loas se escribieron como antesala o umbral de una escenificación más larga, pues bien avanzado en siglo XVII

descripción del triunfal arco que en la solemne entrada [de] Juan Francisco Güemez de Horcasitas... virrey gobernador y capitán general de esta Nueva España, erigió la sacra, imperial, metropolitana iglesia de esta corte de México... (Colofón:) Impreso por la Viuda de D. Josef Bernardo de Hogal. Año de 1746 (Medina, IV, 525; V, 39). empiezan a aflorar casos donde la loa se convierte en la parte central del espectáculo, sin más aditamentos dramáticos» (2014, 116). El otro aspecto diferenciador innegable es su función ecfrástica y explicativa: las loas de carro triunfal -al igual que las de arco- cumplen (además de la laudatio) con la función de describir y descifrar los elementos mitológicos, religiosos o icónico-verbales, esto es, emblemáticos ${ }^{19}$, dispuestos en el carro y que sirven de decorado escénico a la misma representación de la loa. La mayor parte de loas de carro o arco triunfal «ha[n] de ser por fuerza más sencilla[s] y estática[s], pues en el fondo toda[s] ella[s son] una demorada explicación de los elementos decorativos del arco. En este [tipo de textos] hay más écfrasis que teatro, más poesía ecfrástica que dramaticidad, lo cual no evita en absoluto que sea una loa al uso propia de entradas regias y arcos triunfales» (Zugasti 2014, 140). Esta característica produce una interdependencia entre el texto de las loas y la descripción del aparato efímero (el carro o el arco), pues ambos entran en simbiosis para la creación y comprensión del sentido global de la puesta en escena.

Hechas estas consideraciones, veamos de qué manera se manifiestan estos rasgos en las loas de esta fiesta queretana.

\section{IV}

Todas las loas -como es lógico suponer- están determinadas por la situación comunicativa en la cual se insertan: la celebración de la llegada de agua gracias a la construcción del acueducto debida a la generosidad del marqués de la Villa del Villar del Águila. Por ello, como telón de fondo, tanto en el programa simbólico de los carros como en los textos de las loas, se encuentra el motivo del agua, elemento sobre el cual -sea en clave mitológica, bíblica o incluso sacramental- se construirá una ficción de mínima acción dramática, que desarrollará la alabanza en dos claras direcciones: hacia la ciudad, transmutada siempre en espacio dramático paradisíaco, y hacia el marqués y sus virtudes como benefactor.

Las loas de menor complejidad son las monologadas con intervención ocasional de la música. Se trata

19. Debo aclarar que el programa alegórico de los carros no siempre se vale expresamente del emblema, aunque en su construcción se recurre a las estrategias de la emblemática aplicada. 
de las nombradas en la Relación peregrina como Loa del carro de Manuel de Portugal (un sastre pobre) y Loa del gremio de los indios ${ }^{20}$. La primera se representó sobre la superficie de un carro que figuraba un barco con «sus remeros por banda en figura de tritones, moviendo los remos con movimiento tan airoso, que al azotar las olas que rodeaban al bien fingido bajel parecía que se deshacían en lágrimas, sin faltar a las olas el ceño de las encrespadas espumas, que hacían más bien vistos los aciertos de las imitación» (Navarrete 73); en la popa iba Neptuno, sentado en un suntuoso trono, y por acompañamiento, su corte marina: nereidas, sirenas y tritones montados en caballos, cuyos jaeces trataban de imitar «las olas del océano». El acompañamiento musical se compuso de violines tocados por las sirenas. Un «Monstruo marino que iba sentado a los pies del dios Neptuno, dijo la loa» (75) con muy viva expresión. El texto inicia con una intervención cantada por la Música y a continuación un estribillo, a cargo al parecer de un coro, que pudo haber estado constituido por las mismas nereidas, sirenas y tritones. Ambos -parlamento cantado y estribillo- funcionan a modo de introducción en que se explicita, por una parte, la elección del paradigma mitológico en que se funda la loa y el decorado alegórico del carro, y, por otra, el destinatario de la laudatio, simbolizado, en este caso, en el dios Neptuno.

El cuerpo de la loa se encarga -en estilo jocoserio- de descifrar el sentido alegórico del carro y de presentar la alegría y fortuna de la ciudad por tener su acueducto, que la transforma de jardín en paraíso, gracias a la liberalidad del marqués: "La cańada a voces dice / que su madre es una peńa, / su padre un charco lodoso / convertido ya en alberca. / Y con ser de ruines padres, / tal de la plata es la fuerza, / que se ve ya maravilla, / la que flor de berro era" (78). Concluye la loa con una petición -también cantada- de parabienes al sujeto del encomio: $" Y$ si el obrar bien merece / por premio la vida eterna, / pues tan bien ha obrado, iviva, / triunfe, reine, mande, venza» (79).

La Loa del gremio de los indios es la única que no se representó en un carro triunfal y, por lo tanto, no contó con el apoyo visual de una escenografía. Su acompańamiento se conformó por escuadrones militares de indios otomíes y chichimecas vestidos a la usanza indígena combinada con la romana. El

20. Ambas se escenificaron el primer día de la fiesta (17 de octubre), una por la mańana y la otra por la tarde. asunto se basa en el sacramento del bautismo, cuya agua salvífica "a los indios se la dieron, / para que vivieran limpios / de crueldades y torpezas, / de inmundicias y de hechizos» (82). Junto al reconocimiento de su pasado religioso errado, se observa un dejo de reclamo hacia el español, a la vez que de reivindicación indígena: «Los indios siembran los campos, / los indios cogen los trigos, / los indios hacen el pan / y todo lo hacen los indios. / Y es cierto que si faltaran / indios en estos dominios, / faltara todo, porque ellos / son el quinto elemento» (82). $\mathrm{Y}$ en términos un tanto satíricos - pues fueron los indios los constructores del acueducto-, manifiestan al español: «Y hoy los indios se la vuelven [el agua], / porque tengan entendido / que si es pura, es porque vivan / los españoles sin vicios» (82). La ciudad también es presentada como un "hermoso paraíso», donde se verán «Las azucenas, las rosas, / los jazmines y los lirios, / convertidos ya en estrellas» (82).

Los otros cuatro textos: Loa del carro de los cirujanos y barberos, Loa del carro de los panaderos y trapicheros, Loa del carro de los sastres y Loa de los carpinteros $y$ herreros, resultan más interesantes en cuanto a la integración de la música y el canto en el discurso verbal (particularmente la primera y la tercera loas), así como presentan un mayor movimiento escénico, pues se trata de loas dialogadas, con la intervención desde dos y hasta siete personajes ${ }^{21}$, que desarrollan el elogio de la ciudad y del marqués, dos de ellas - primera y tercera loas- siguiendo un esquema de debate, si bien no siempre logrado; además de que el programa simbólico de los tres últimos carros es más elaborado, con la presencia no sólo de figuras de bulto y al «vivo», es decir, actores, que conforman especie de apariencias mixtas - parte estáticas y parte en movimiento-, sino también de diversos emblemas y poemas sueltos que serán asimismo explicados en el desarrollo de las loas ${ }^{22}$.

21. Es el caso de la Loa de la loa del carro de los sastres. En la nómina de personajes, se enlistan sólo seis, pero en el texto tiene una brevísima intervención Tritón: apenas tres versos acompańados de música de clarín, tocado por el mismo personaje, que formaba a la vez parte del decorado simbólico de este carro triunfal.

22. A este respecto, vale la pena citar un fragmento sobre la Loa de los panaderos y trapicheros: «La loa la trazó el ingenio con tal discreción, que ella fue dando a entender por menor cuanto contenía el carro, así en las partes todas de su estructura, como en las poesía que lo adornaban; circunstancia que le acarreó aquellos elogios que suele dar hasta la 
Para la Loa del carro de los cirujanos y barberos (escenificada el 18 de octubre), el carro recreaba el monte Helicón, y en «lo más elevado de su cumbre, se registraba el caballo Pegaso, batiendo unas grandes alas de blancas plumas, como para volar a tomar asiento entre las estrellas; con un pie hería la cumbre de aquel monte Helicón, y se veía brotar la fuente Hipocrene, que mormurando por verse precipitada de la altura, serenaba el cristalino ceño al besar las plantas del dios Apolo y las nueve musas» (Navarrete 83-84). Esta composición estática del monte y las figuradas musas, se complementaba con la presencia de un actor que hacía el papel de Apolo, caracterizado de acuerdo con su tradición iconográfica: «tenía el cabello rubio como los rayos del sol; ceñía la cabeza con una corona de laurel; en la mano tenía una cítara, y el vestido era de tela de oro para imitar los resplandores de que se viste cuando sale de gala por el oriente para visitar y alumbrar al mundo" (84). El acompañamiento estaba conformado por «la clase de cirugía y flobotomía ${ }^{23}$ o de los cirujanos y barberos, que montados en briosos caballos aumentaban la majestad del paseo con sus bien compasados movimientos» (84).

La loa estuvo a cargo de cuatro personajes en debate: Apolo, la Cirugía, la Flebotomía y la Música, y su principal cualidad es que su texto alterna no sólo fragmentos de cantado con representado, sino se especifican en las acotaciones segmentos en estilo recitativo o rappresentativo, procedente de la tradición operística italiana: «Flobotomía canta recitado», "Cantando Flobotomía», "Canta Apolo», «Recita [Apolo]» (86), "Canta Cirugía», "Recita Cirugía» (87). Por otro lado, es la única que tiene una acotación que implica la aparición elevada de dos personajes: "Aparece en lo alto del monte Helicón la Cirugía y la Flobotomía en traje de ninfas» (86), para después marcar -en didascalia implícita- su desplazamiento hacia lo bajo del escenario: dice Cirugía: "Yo de su monte a la sombra», y luego Flebotomía: "Yo de su fuente a la orilla». Se sobreentiende que mientras descienden "cantan recitando", esto es, en estilo recitativo.

En la modalidad cortesana es frecuente encontrar loas en las cuales «el asunto dramático se funda en

ignorancia cuando percibe con claridad lo que con impaciencia desea entender» (Navarrete 136).

23. Flobotomía, esto es, flebotomía, el "Arte de sangrar o la misma sangría. Es voz griega que vale sección de venas» (Autoridades). Mantengo la forma flobotomía en todas las citas. un debate simbólico que enfrenta a dos o tres personajes alegóricos que se disputan el mecenazgo de la fiesta» (Farré 122); la situación se resuelve con la mediación de otro personaje que asume la función de juez. En esta Loa de los cirujanos y barberos, el debate, sin embargo, no queda del todo bien estructurado. Al inicio, la Música -oculta-y Apolo convocan sucesivamente a la Musas -figuras estáticas que integran la composición alegórica del carro- para que, por una parte, solemnicen la llegada del agua, $y$, por otra, funjan como jueces del enfrentamiento entre Flebotomía y Cirugía por la primacía del festejo. Ambas solicitan primero el favor inspirador de Apolo para luego discurrir a cuál de los elementos presentados por ellas mismas, agua o fuego, se debe el líquido puro que la ciudad goza. Abruptamente el intento de disputa -pues no llega en realidad a más que la presentación- es interrumpido por Apolo, que introduce el aire y la tierra y completa así la serie de los cuatro elementos, otorgándoles igual mérito en el suceso celebrado, pues, por una parte, son causa de la llegada del agua ${ }^{24}$, y, por otra, símbolo de las virtudes del marqués ${ }^{25}$. De este modo, Apolo es a la vez participante en el debate y voz de las figuradas musas-jueces que resuelve la confrontación en elogio de Juan de Urrutia y reiteración del motivo celebrado.

El carro de los panaderos y trapicheros - con escuadrón a caballo y acompañamiento de timbales y clarines por delante- tenía notas más populares y locales, empezando por la «fachada principal que tenía la figura de una jarra, que, al paso que divertía los ojos, hacía agudo reclamo al entendimiento para que conociera la propriedad de lo alusivo» (Navarrete 127); su decorado alegórico reproducía fielmente una de las pilas de agua localizada en la llamada Plaza de la Cruz con su Virgen del Pilar y debajo de ella un león que arrojaba agua por la boca. En un nivel más bajo se «miraba el señor marqués, sentado sobre la blanca espalda de una parda y hermosa águila» (128) y a los lados de ésta Neptuno, que otorgaba tridente por cetro y corona de laurel, y su esposa

24. «Y aun por esto esta agua goza (aunque el hipérbole asista) de los elementos cuatro, / pues su especiosa arquería / de la tierra se levanta, / y tan alta la sublima, / que, habitadora del aire, / pasa al fuego y lo visita. / Y para que no se dude / que viene de tan arriba, / trae de la ardiente región / algún calor por noticia» (Navarrete 88 ).

25. "Porque es el señor marqués / del Villar, que siempre viva, / mar y fuego que la vierte, / tierra y aire que la envía» (Navarrete 87). 
Anfitrite, que ofrecía a Juan de Urrutia el título de duque en un terceto. En los laterales del carro se imitaron -cuatro por lado- los arcos del acueducto, y sobre ellos se colocaron ocho ninfas, cada una con poemas laudatorios al marqués.

La correspondiente loa tuvo lugar el 24 de octubre y se ejecutó entre "Glauco, dios del mar, que representaba, y Flora, diosa de los huertos, que cantaba» (136). Glauco se encarga fundamentalmente de explicar los componentes y el sentido del programa alegórico del carro, en tanto Flora cumple una función de acompañamiento reiterativo, pues se limita a repetir, a manera de eco, las palabras finales de algunos versos, y, como estribillo, los últimos pies de las décimas que declama Glauco.

El carro de los sastres tuvo por acompañamiento un «lucido escuadrón que al sonoro ruido de cajas y clarines marchaba con tan garboso y regular movimiento» (Navarrete 140) sobre caballos ricamente adornados. Ostentaba la fachada principal más elevada de todas (14 varas y media de altura, esto es, más de $12 \mathrm{~m}$ ) y su programa alegórico combinaba elementos religiosos (la Trinidad en un trono franqueado por seis ángeles, todo sobre un sol resplandeciente al cual se acercaba un águila), humanos (un retrato del marqués quien recibía directamente de Dios Padre un «raudal bien fingido de agua» [142], para distribuirlo sobre la ciudad de Querétaro, también plasmada en el lienzo) y mitológicos (Neptuno con sus atributos, un Tritón que tocaba un clarín, Eolo con un abanico y una Ninfa con corona de flores y ramo de espigas y frutas; además otros personajes mitológicos con referente astrológico: la Luna y Acuario).

Su correspondiente texto, Loa del carro de los sastres (representada el 25 de octubre), es el que con mayor mérito logra la estructura de debate entre personajes que se pelean la primacía sobre el suceso festejado. En esta loa serán la Música (que aboga por al Sol), Neptuno, la Luna, Acuario y Eolo, quienes disputen entre sí el mérito de haber llevado el agua a la ciudad. El papel de juez lo desempeña la Ninfa, quien al final otorga el triunfo al verdadero héroe del acontecimiento festivo: el marqués. Cada uno de los personajes expondrá sus razones a manera de disputatio académica: Neptuno, como seńor de los mares, explica que "con esta llave de mano, / abriendo puertas y cauces, / tanto caudal habré dado»; la Luna reclama que «soy el nocturno farol / cuyo imperio, cuyo mando / sobre cristales se asienta, / cuando a mi influjo los astros / en estaciones vierten / o más o menos los vasos, / que en menguantes o crecientes / abro o cierro los erarios»; mientras que Acuario sentencia que «... sólo se debe / tanto favor a un Acuario, / pues inunda liberal / los valles y montes altos», a lo cual replica Eolo, «En vano fuera el intento, / si de los vientos al rapto / no concurrieran» Favonio, Aquilón, Céfiro y Euro ${ }^{26}$. Finalmente la Música reclama el homenaje para «El Sol, de vivientes padre», pues "es el que mueve los astros / y como causa luciente / todos le ofrezcan el lauro» (Navarrete 145). A continuación, la Ninfa da por concluida la presentación de pruebas y a su vez compendia las cualidades del vencedor a través de una serie de enigmas que posteriormente, a solicitud de los contendientes, ella misma explica. El resultado es claro: el merecedor del homenaje es el marqués; la argumentación de los personajes alegóricos y mitológicos constituye sólo distintas perspectivas del encomio a las bondades y virtudes de Juan de Urrutia. El debate se resuelve en forma conciliadora: los participantes de la disputa supeditan sus potestades ante el marqués para posibilitar la construcción del acueducto y la introducción del agua. Otro aspecto a destacar en esta loa es la especializada ejecución de los parlamentos de la Ninfa. En sucesivas acotaciones se especifica: "Canta la Ninfa», "Recita -entiéndase en estilo recitativo- la Ninfa», "Representa la Ninfa» (Navarrete 147). No obstante, la proporción de cantado y recitativo no alcanza el porcentaje que ofrece la Loa del carro de los cirujanos y barberos.

El 1 de noviembre cerró el desfile y la fiesta el carro y su Loa de los carpinteros y herreros. "Iban todos en fogosos caballos, arrojando chispas, como si cada herradura fuera una encendida fragua», símbolo de los herreros, y "marchaban al agradable sonido de cajas y clarines, imitando los roncos golpes del mazo y el mormollo agudo de la asierra, para así avisar al concurso que allí marchaban los carpinteros» (Navarrete 152). La composición alegórica del carro tenía por elemento central a Moisés -simbolizando al marqués del Villar del Águila-, quien con su vara hacía brotar una fuente de agua de una piedra; las nueve musas rodeaban la fuente y "gustosas y alegres tributaban agradecimientos y veneraciones al caudillo hebreo, como autor de prodigio tan raro» (153); a los lados de Moisés se veían cuatro ángeles; en la parte más elevada del

26. Nótese la confusión del desconocido autor de esta loa, que olvida mencionar entre los vientos a Noto (el latino Auster o Austro, viento del Sur) y repite a Céfiro (viento del oeste) y su análogo latino Favonio. 
aparato efímero, se colocó un águila real con las alas desplegadas, y sobre ella la Fama con su clarín. Completaban el significado del programa varios poemas dispersos en el carro.

En el texto de la Loa del carro de los carpinteros y herreros se advierten dos tipos de ejecución verbal: cantado y representado o declamación teatral, pero no queda claro si se trata de uno o de dos personajes. En el cuerpo de la loa únicamente se nombra a Música como posible personaje, pero sus intervenciones, que no son pocas, se limitan la mayoría a un verso, y tan sólo hay una acotación que pide: «Representa» (157); se sobreentiende - por la secuencia textual- que se refiere a la Música, pues antes había cantado. El resto del texto no presenta marcas de personaje. Todo parece indicar que se trata de una loa-como la de Juan de Portugal y la del paseo de los indios- monologada con dos posibilidades de realización: que el personaje Música actúe y cante el texto, y en este caso las marcas de "Música» signifiquen no el turno del personaje sino la acotación que exige el canto del verso: «Música: Que vino por la corriente», "Música: El marqués vino por agua», «Música: A Moisés que lo hizo bueno» (157, 158); la otra opción es que sólo represente Música y que todos los fragmentos de canto, identificados con el término "Música», sean ejecutados por un acompañamiento de músicos ocultos, aunque queda un segmento de canto que exige -en esta solución- la participación del personaje Música, pues no se explicaría de otro modo la acotación -ya señalada- que indica el cambio de cantado a representado:

\author{
MúsICA ¿Quién es el héroe bizarro \\ que quitar tus faltas sabe? \\ ¿El que es digno que se alabe, \\ y se figura en el carro? [...] \\ Representa \\ Es quien allí se figura \\ en Moisés hasta en el nombre, \\ Y es como Moisés un hombre, \\ Como dirá la Escriptura. (Navarrete 157)
}

Cabe por último mencionar que los versos cantados suelen reiterar una virtud del marqués-Moisés.

\section{VI}

El estado actual de los estudios en torno a la loa novohispana es fragmentario: sólo unos cuantos autores como Fernán González de Eslava (1998),
Sor Juana Inés de la $\mathrm{Cruz}^{27}$, Juan de la Anunciación (Yhmoff Cabrera 1985, García Gómez 2010), Lorenzo del Santísimo Sacramento (Pascual Buxó 2000) o Cayetano Cabrera y Quintero (Parodi 1976) han merecido acercamientos críticos y la edición -no siempre completa- de su producción panegírico-dramática breve; por otro lado, hay que señalar también que no contamos todavía con el puntual registro bibliográfico que dé cuenta de la totalidad representada y conservada de este género, ni con las suficientes ediciones que permitan establecer todas sus modalidades y reconstruir su proceso evolutivo. Parte de estas dificultades se advierte en el tipo de loa que he tratado en estas páginas: la loa para carro triunfal, que bien podría englobarse en el membrete loa para aparato efímero, pues en esta categoría debería asimismo considerarse la de arco triunfal y aun otras más esporádicas, pero de las que es posible rastrear si no textos sí documentación de su efectiva representación, como las llevadas a cabo para retablos o altares y otras construcciones similares de naturaleza perecedera o efímera.

En el caso específico de las loas para carro -y para arco triunfal, quizá la variante más cercana-, a pesar de tener testimonios documentales fehacientes de su escenificación desde principios del siglo $\mathrm{XVII}^{28}$ y hasta el siglo XVIII, los textos conservados no han sido -en términos generales- considerados parte del género dramático. Dos razones principales, en mi opinión, han determinado este hecho: la escasa introducción

27. De Sor Juana son copiosos los trabajos críticos sobre sus loas y me limito a referir, por ser uno de los pioneros y al cual se sigue recurriendo, la sección correspondiente del «Estudio liminar» de Méndez Plancarte al vol. III de las Obras completas de la monja (1994 [1a. ed.: 1954]).

28. Por ejemplo, las realizadas por la Compañía de Jesús para los cinco carros triunfales que desfilaron en 1610 por las calles de la ciudad de México con motivo de la beatificación de Ignacio de Loyola. De manera parecida a la que he descrito para la fiesta queretana, los personajes de las loas formaban parte del decorado alegórico de los carros y luego representaban su respectiva loa-llamada triunfo, aunque enfatizada su brevedad-, pero con la salvedad de que el escenario no fue la efímera construcción móvil, sino tablados erigidos a intervalos en el trayecto de la procesión y adornados con profusión de papeles con emblemas y jeroglíficos que -se reitera enfáticamente- aludían al programa simbólico de cada carro (véase Hernández 2007). Posterior a esta fecha, en ocasión de la canonización de Francisco de Borja, de nueva cuenta los jesuitas organizaron un desfile de carros triunfales -también cinco-acompañados de sus respectivas loas (Festivo aparato 3r-16v). 
de los textos -sobre todo los impresos- con la expresa denominación de loa, y su poca acción dominada por las funciones laudatoria y ecfrástico-explicativa en directa relación con la arquitectura efímera que le sirve a la vez de referente y marco escénico de la mínima ficción que desarrollan.

No obstante, una revisión más minuciosa de este tipo de textos breves y de los relatos festivos en los cuales por lo común se inserta permite establecer, en primer lugar, la plena conciencia de sus autores de escribir obras para ser representadas, ya por actores profesionales, ya por aficionados (sobre todo miembros de corporaciones religiosas o civiles y estudiantes de colegios religiosos) ${ }^{29}$, que se apoyan -casi siempre- en variadas formas de música ${ }^{30} \mathrm{y}$-en ocasiones- también de danzas, así como en recursos escenotécnicos adosados a las estructuras efímeras (puertas o ventanas -a manera de bofetones- que se abren o cierran para mostrar personajes o utilería escénica; uso de poleas, canales, planos inclinados o escalinatas que permiten el ascenso y descenso de personajes, algunas veces en tramoya de nube $)^{31}$; varias recurren a didascalias explícitas e implícitas que determinan el movimiento escénico de los personajes, el tipo de ejecución (declamación, canto, recitativo) o el tipo de vestuario y atributos ${ }^{32}$, y a

29. En ocasiones se mencionan niños en traje de ángel como personajes de loas para arco triunfal, y para loas llevadas a cabo en conventos femeninos se refieren niñas que se criaban o educaban en tales recintos religiosos.

30. En un «carro de los nueve coros de los ángeles, todos [iban] con variedad de instrumentos en las manos y con tal melodía de voces (formada por un escogido terno de músicos que iban ocultos), que no parecía capilla de la tierra la que tanto suspendía con sus asonancias y deleitaba tanto con sus bellezas» (Festivo aparato 16r).

31. "A la mano derecha desta portada había un tablado, y a él llegar su excelencia se abrió una nube y dentro de ella un ángel, que en nombre de la ciudad de los Ángeles dijo una loa angelical en latín y en romance; y era tal la loa, que mereció muchas» (Gutiérrez de Medina 29v). «Uno de los ángeles de nuestra ciudad salió a vuelos de una nube, hecha a propósito a la mano izquierda del arco, en un globo o cielo, y recitó la explicación» (Galindo 24r).

32. Véanse los ejemplos ya citados a propósito de las loas aquí comentadas, o este otro de una loa también para carro triunfal de 1730: «El representante y la Música» (Jiménez de Bonilla 137). Un peculiar caso del empleo de la didascalia implícita para marcar un cambio de vestuario y, por lo tanto, de personalidad: de México a Minerva, ante los espectadores, lo tenemos en la loa para el arco triunfal intitulado Astro mitológico politico de 1650. Inicia la loa una cómica en el personaje de México y hacia la última parte del texto pesar de que la mayoría son monologadas, hay también dialogadas con la participación de hasta siete personajes (hasta donde he podido documentar), lo cual las dota de mayor dinamismo escénico, aunque no siempre de un argumento más elaborado. En segundo, las descripciones que enmarcan estas loas confirman su recepción de época como piezas dramáticas y con frecuencia se aluden las cualidades de su representación: destreza actoral, comentarios acerca de la variedad y acierto en el vestuario y en el decorado escénico, elogios al emotivo y logrado manejo vocal de los segmentos cantados o recitativos, así como la buena ejecución de la música que suele acompañar su puesta en escena ${ }^{33}$.

muestra su turbación, que antecede su transformación, en estos términos: "¿Mas qué es esto? ¿A qué grandeza / me arrebatan mis impulsos? / $\mathrm{Al}$ aspecto de tus luces en deidad me transfiguro. / [...] Ya que mejoro mi suerte / y naturaleza mudo, / quiero desechar a un tiempo / la forma y ropaje inculto. / [...] Ya me contemplo Minerva...» (Alavés 8v [foliación de la segunda fachada]). La descripción completa la presentación del personaje y puntualiza el cambio de vestuario y atributos: "Descripción del arco que se recitó en figura de México, vestida en traje de india con naguas de lama encarnada y oro, guarnecidas con puntas de oro y plata y pluma, que después, despojándose imperceptiblemente deste ropaje en el mismo teatro, prosiguió en la relación transformada en la diosa Minerva, armada con peto, espaldar y gola y faldones de tela azul y oro, que empuñando una asta y embrazando un escudo representó a la diosa y desapareció por tramoya» $(7 \mathrm{r})$.

33. Para uno de los arcos levantado en 1640, la explicación «estuvo prevenida entre Mercurio y la América vistosamente adornados de sus conocidos trajes y insignias, en breve diálogo" (Descripción y explicación 17r-v). En 1672 se comenta acerca del que "hacía el papel de San Francisco de Borja, un buen dispuesto joven de capa y espada con el fausto que pedía la representada grandeza», y que dijo «con grave suspensión, pero notable propiedad de voz y acciones señoriles» la loa (Festivo aparato 15r, 15v). En tanto que «determinado de recitar su loa, para hablar en nombre de todos, su poderoso monarca, Moctezuma, se encaró con el sol prorrumpiendo con lindo aire y tono estas métricas voces" (Festivo aparato 14v). Para la canonización de San Juan de la Cruz también se preparó un carro con su loa, para la cual se especifica: «Por entre la nube del trono salía el que representó la loa garbosamente adornado y muy diestro en el arte del decir, y después de haber cantado la Música una letra muy a propósito empezaba a recitar este romance» (Jiménez de Bonilla 135). Y Navarrete indica para una de las loas queretanas: «El cuerpo de la loa es como se sigue, quedándonos el sentimiento de que la imprenta no le pueda dar la alma que le infundió la voz» (76). 
Y a propósito de la presencia de la música -ya de acompañamiento, ya cantada, ya de tipo operísticoen el género loa, tampoco contamos - para el caso novohispano- con un estudio integral que oriente sobre sus diversas tradiciones, funciones y modalidades. El uso del canto y la música en el teatro -es bien sabido- era común y en algunos casos característico de ciertos géneros dramáticos, y cumplían en general ciertas funciones como explicitar el estado anímico de personajes: turbación, miedo, duda; hacer explícita la presencia de un mundo sobrenatural, tanto divino como demoníaco; marcar la calidad de ciertos personajes, sobre todo mitológicos; pero más frecuentemente se trataba de un aderezo más de la función teatral. Aunque las loas de Sor Juana constituyen un significativo antecedente del profuso empleo de la música y el canto (ya en voz de personajes, ya en la de coros), siguiendo la estela calderoniana y que de hecho podrían considerarse dentro de la categoría que Flecniakoska denomina loa zarzuelizada (129) $)^{34}$, sólo hay en su producción dramática dos acotaciones que exigen el estilo recitativo $^{35}$ : una en la numerada por Méndez Plancarte como tercera Loa a los años del rey (v. 119: «[El Cielo] Cantando: recitativo") y la otra en el auto sacramental de El divino Narciso (v. 767: «Acaba de subir Eco, y dice cantando en tono recitativo»).

Como he tratado de evidenciar en las páginas antecedentes, en la muestra de loas queretanas se encuentra una implícita voluntad de integración y estructuración armónica entre la actuación, el canto y el acompańamiento musical. El estilo recitativo o rappresentativo surge precisamente como una modalidad vocal que busca integrar la declamación teatral y el canto, para mover los afectos y distinguir la calidad elevada de los personajes, o para decirlo con las conocidas palabras que preceden a la primera intervención de Mercurio y Palas en el segundo acto de Fortunas de Andrómeda y Perseo de Calderón de la Barca: «empezaron su plática, a diferencia de los humanos, en un estilo recitativo, que siendo un compuesto de representación y música, ni bien era música ni bien representación, sino una entonada consonancia a quien acompañaba el coro de instrumentos» (64). Si hacia principios del siglo XvIII novohispano

34. Aquella que en el ámbito cortesano se transforma en manos de Calderón casi en «una égloga o zarzuela reducida de tono serio», una "apertura musical y culta» (Flecniakoska 103).

35. No obstante, muchos fragmentos de las loas que piden su ejecución cantada podrían haber sido en recitativo italiano. se han documentado los primeros intentos -sin mayor trascendencia- de aclimatación de la ópera con El Rodrigo (1708) ${ }^{36}$ y La Parténope (1711), con partituras del presbítero Manuel Sumaya, para trazar la introducción y adopción de los estilos italianos en la musicalización de piezas teatrales breves, específicamente de la loa y sus subgéneros, no contamos por desgracia con los datos necesarios. Antes de la fecha de escenificación de estas loas para carro triunfal (1738), no he podido rastrear -exceptuando los ejemplos citados de la Décima Musa- alguna loa que contenga marcas o acotaciones del estilo recitativo $^{37}$. Aunque posterior a este año he documentado por lo menos un par de textos -loas que anteceden e introducen obras mayores- que acotan no sólo la ejecución de recitativos sino también de arias: es el caso de la Loa en celebridad de pascuas $^{38}$ y de la Representación panegírica (c. 1756) de Cabrera y Quintero $^{39}$. Otro ejemplo fue recientemente dado a

36. En opinión de algunos críticos, se trata de una zarzuela o melodrama, pero no de una ópera.

37. Es interesante señalar que el recitativo y el aria se adoptaron primero en la música sacra novohispana hacia finales del siglo XVII. Marín data este proceso italianizante entre 1690 y 1730, previo a la elaboración de nuestras loas; mientras que Saldívar afirma que "poseemos un manuscrito de la poesía de un oratorio de ese estilo [italiano] y ostenta todos los caracteres de ser del siglo XVII [...]; lleva por título: Letra a la Imagen Soberana de Nuestra Señora del Rosario [y en ella] alternan arias y recitativos» (167). Se sabe que sobre todo hacia la segunda mitad del siglo xviII, algunos músicos y maestros de las catedrales se desempeñaron asimismo como músicos del coliseo de la ciudad de México, pero aún no se ha explorado suficientemente esta vía que podría arrojar luz acerca de la musicalización a la italiana en los géneros dramáticos.

38. La loa no está fechada, por cual no se puede descartar por completo que su escritura y representación hayan podido verificarse antes de 1738. El título completo: Loa en celebridad de pascuas en el Convento de nuestro padre San Juan de Dios para la comedia de Apeles y Campaspe: Darlo todo y no dar nada. En el texto se leen acotaciones del tipo: «Sigue la aria la Fama», "Aria [entre Pintura y Poesía]», "Canta la Poesía recitando», "Recitando [la Poesía]» (Cabrera y Quintero 185-186).

39. La Representación panegírica a los excelentísimos marqueses de las Amarillas, virreyes de esta Nueva España, en su recibimiento en el Monasterio de la Purísima Concepción de México se llevó a cabo al parecer en 1756, año en que los marqueses también visitaron el Convento de San Jerónimo y cuyo festejo teatral -manuscrito- ha sido editado por Luciani (2015). En esta loa encontramos las siguientes didascalias explícitas: «Recitado [de Talía, Eufrosine y Aglaya]», «Aria [de las tres Gracias]», "Aria [de Talía]», «Recitado que canta Iris», 
conocer por Luciani como parte de un festejo teatral completo dedicado en 1756 a los marqueses de las Amarillas en el convento de San Jerónimo. En palabras de este crítico, «la música no predomina y tampoco se emplea el recitativo», no obstante, «la influencia de la ópera italiana se percibe en las arias cantadas antes y después de la loa (pero no incorporadas a ella)» (44). Vale la pena mencionar un último caso, que a pesar no formar parte de una loa, representa -me parece- un indicio del proceso de musicalización al modo italiano que hacia las primeras décadas del siglo Xviı afectará no sólo los géneros dramáticos sino también los líricos. Se trata del Certamen académico que en 1730 los carmelitas convocaron como parte de los festejos por la canonización de San Juan de la Cruz. En esta palestra se recurrió a una serie de composiciones poéticas breves puestas en música "por los más peritos maestros de la arte», que introdujeron el certamen y cada uno de los ocho asuntos puestos a concurso; su estructura constaba de una presentación que cifraba el tema en estilo recitativo y a continuación una conclusión en forma de aria que exhortaba a los contendientes a la lid académica ${ }^{40}$ :

\section{Asumpto SEgundo}

Música (Recitado) Suspende el Proteo divino a todo humano concepto en varias transformaciones con que mira al universo: ya de joven generoso, ya de basilisco fiero, ya de águila caudalosa y ya de león que sangriento en el circo de las letras quiere ser asumpto excelso.

(Aria) Para cuyo fin os llama diciendo: ¡venid a la lid, donde haga el ingenio alarde dichoso de su vencimiento.

(Jiménez de Bonilla 588)

esta misma acotación es repetida más adelante (Cabrera y Quintero 227, 235, 239).

40. La excepción fue la primera composición que presentaba recitado, aria y recitado.
Considero, en conclusión, que el conjunto de textos dramáticos queretanos, cuyos rasgos más sobresalientes he intentado bosquejar, conforman un breve pero significativo repertorio de las posibilidades que tuvo la loa para carro triunfal en la praxis dramática novohispana, y constituyen un importante eslabón en el proceso de musicalización a la italiana de este género breve en la Nueva España.

\section{Bibliografía}

Alavés Pinelo, Alonso de. Astro mitológico politico, que en la entrada y recebimiento del excelentísimo señor don Luis Henríquez de Guzmán, virrey lugarteniente del rey nuestro señor, gobernador y capitán general de esta Nueva España... consagró la ilustrísima, nobilísima y muy leal ciudad de México... en el arco triunfal que erigió por trofeo a la immortalidad de su memoria. México: Juan Ruiz, 1650.

AnunCiación: ver Juan de la Anunciación.

Ayala Echávarri, Rafael. Bibliografía histórica y geográfica de Querétaro. México: Secretaría de Relaciones Exteriores, 1949.

Cabrera y Quintero, Cayetano Javier de. Obra dramática. Teatro novohispano del siglo XVIII. Claudia Parodi (ed.). México: UNAM, 1976.

Descr[i]pción y explicación de la fábrica y empresas del sumptuoso arco que la .. ciudad de México... erigió a la feliz entrada y gozoso recebimiento del excelentísimo señor don Diego López Pacheco... visorrey y capitán general desta Nueva España... México: Viuda de Bernardo Calderón, 1641.

DRAE. Diccionario de la lengua española. Madrid: Real Academia Española-Espasa-Calpe, 1992.

Calderón de la Barca, Pedro. Andrómeda y Perseo. Fábula representada en el Coliseo del Real Palacio del Buen Retiro. Rafael Maestre (ed.). Almagro: Museo Nacional del Teatro, 1994.

Cotarelo y Mori, Emilio. Colección de entremeses, loas, bailes, jácaras y mojigangas desde fines del siglo XVI a mediados del XVIII. Madrid: Bailly-Baillière, 1911. 2 vols.

FarRé Vidal, Judith. Dramaturgia y espectáculo del elogio. Loas completas de Agustin de Salazar y Torres, vol. I. Estudio. Kassel: Reichenberger, 2003.

Festivo aparato con que la Provincia Mexicana de la Compañia de Jesús celebró, en esta imperial corte de la América septentrional, los immarcesibles lauros y glorias immortales de San Francisco de Borja, grande en la pompa del mundo, mayor en la humildad de religioso y máximo en la gloria de canonizado... México: Juan Ruiz, 1672. 
Flecniakoska, Jean Louis. La loa. Madrid: Sociedad General Española de Librería, 1975.

Galindo, Mateo. Fuerte sabia politica que la... ciudad de Los Ángeles erigió en arco triunfal al excelentísimo señor don Diego Roque López, Pacheco, Cabrera y Bobadilla, primer marqués de España, y consagró en su deseada venida por virrey, gobernador y capitán general desta Nueva España. México: Viuda de Bernardo Calderón, 1641.

García Gómez, María Eugenia. Poesía dramática de fray Juan de la Anunciación. Edición y estudio de loas carmelitas del siglo XVIII. México, 2010 [Tesis de doctorado, Facultad de Filosofía y Letras, Universidad Nacional Autónoma de México].

García Ugarte, Marta Eugenia. Querétaro: historia breve. México: El Colegio de México-Fondo de Cultura Económica-Fideicomiso Historia de las Américas, 2011.

González de Eslava, Fernán. Coloquios espirituales y sacramentales. Othón Arroniz Báez (ed.) y Sergio López Mena (colab.). México: Universidad Nacional Autónoma de México, 1998.

Gordo Peláez, Luis J. «Fábrica y fama de los acueductos novohispanos: de la peregrina 'Targea' y 'Arcos' de Santiago de Querétaro». Santiago Huerta Fernández (coord.). Actas del Séptimo Congreso Nacional de Historia de la Construcción, Santiago de Compostela, 26-29 octubre de 2011, vol. I. Madrid: Instituto Juan de Herrera, 2011: 623-632.

Gutiérrez de Medina, Cristóbal. Viaje de tierra y mar, feliz por tierra y mar, que hizo el excelentísimo señor marqués de Villena, mi señor, yendo por virrey y capitán general de la Nueva España... México: Juan Ruiz, 1640.

Hernández Reyes, Dalia. «El teatro de la Compañía de Jesús en las festividades religiosas de la Nueva España (1600-1630)». José Pascual Buxó (ed.). Reflexión y espectáculo en la literatura virreinal. México: Universidad Nacional Autónoma de México, 2007: 315-332.

Jiménez de Bonilla, Joaquín, Ozaeta y Oro, José Francisco, y Aguirre, José Francisco de. El segundo quince de enero de la corte mexicana. Solemnes fiestas que a la canonización del místico doctor San Juan de la Cruz celebro la Provincia de San Alberto de Carmelitas Descalzos de esta Nueva España... México: José Bernardo de Hogal, 1730.

Juan de la Anunciación, Fray. Poemas religiosos y profanos de fray Juan de la Anunciación del convento de la Purísima Concepción de los Carmelitas Descalzos de la Provincia de San Alberto de Sicilia en Toluca, durante los años de 1721 a 1724. Jesús Yhmoff Cabrera (ed.). Toluca: Gobierno del Estado de México, 1985.

Juana Inés de la Cruz, Sor. Obras completas, vol. III. Autos y loas. Alfonso Méndez Plancarte (ed.). México: Fondo de Cultura Económica-Instituto Mexiquense de Cultura, 1994.

Luciani, Frederick (ed.). Joaquín Barruchi y Arana, Relación del festejo que a los Marqueses de las Amarillas les hicieron las Señoras Religiosas del Convento de San Jerónimo (México, 1756). Madrid-Frankfurt-México: Iberoamericana-Vervuert-Bonilla, 2011.

Maldonado, Humberto. «La evolución de la loa en la Nueva España: de González de Eslava a Sor Juana». Ysla Campbell (ed.). El escritor y la escena: Actas del I Congreso de la Asociación Internacional de Teatro Español y Novohispano de los Siglos de Oro. México: Universidad Autónoma de Ciudad Juárez, 1993: 77-94.

Marín López, Javier. «Una desconocida colección de villancicos sacros novohispanos (1689-1812): el Fondo Estrada de la Catedral de México». María Gembero Ustárroz y Emilio Ros Fábregas (eds.). La música y el Atlántico. Relaciones musicales entre España y Latinoamérica. Granada: Universidad de Granada, 2007: 311-357.

Medina, José Toribio. La imprenta en México, 15391821, vols. III, IV, V. México: Universidad Nacional Autónoma de México, 1989.

Méndez Plancarte, Alfonso. «Estudio liminar». Sor Juana Inés de la Cruz, Obras completas, vol. III. Autos $y$ loas. México: Fondo de Cultura Económica-Instituto Mexiquense de Cultura, 1994: VII-XCVIII.

Monterde, Francisco. Bibliografía del teatro en México. México: Imprenta de la Secretaría de Relaciones Exteriores, 1933.

Monterde, Francisco. «Preámbulo». Francisco Antonio Navarrete, Relación peregrina. México: Bibliófilos Mexicanos, 1961: 7-11.

Moreno Pérez, Edgardo. Apuntes para una historia del teatro y las artes escénicas en Santiago de Querétaro del siglo XVI al siglo XIX. Transformaciones y continuidades sociales, culturales y memoria colectiva. Santiago de Querétaro: Instituto Queretano de la Cultura y las Artes, 2006.

Navarrete, Francisco Antonio. Relación peregrina de la agua corriente que para beber y vivir goza la muy noble, leal y florida ciudad de Santiago de Querétaro... Describense las plausibles fiestas que dicha nobilisima ciudad, como agradecida, hizo al ver logrado tan peregrino y perenne beneficio. Y dedica este cristalino monumento de su gratitud a la ilustre señora doña María Paula Guerrero Dávila, marquesa de la Villa del Villar del Águila. 
México: José Bernardo de Hogal, 1739. [Accesible en Cervantes Virtual: http://www.cervantesvirtual. com/obra/relacion-peregrina-de-la-agua-corrienteque-para-beber-y-vivir-goza-la-muy-noble-leal-y-florida-ciudad-de-santiago-de-queretaro--0/].

Navarrete, Francisco Antonio. Relación peregrina de la agua corriente, que para beber y vivir goza la muy noble, leal y florida ciudad de Santiago de Querétaro. Sergio Francisco Rosas Salas, Emilio Zúníga Solís y Max Sigg Vega (eds.). Querétaro: Municipio de Querétaro, 2013.

Ortiz Bullé Goyri, Alejandro. «El Marqués de la Villa del Villar del Águila y las fiestas del agua en Querétaro en 1738». Teatro y vida novohispana. Siete ensayos. México: Universidad Autónoma Metropolitana, Azcapotzalco, 2011: 105-117.

Pascual Buxó, José. Un desconocido dramaturgo novohispano del siglo XVIII. Dos loas de fray Lorenzo del Santísimo Sacramento. México: Universidad Nacional Autónoma de México, 2000.

Pasquariello, Anthony M. «The Evolution of the Loa in Spanish America». Latin American Theatre Review, 3.2 (1970): 5-19.

Ramírez Montes, Mina (ed). Querétaro en 1743: informe presentado al rey por el corregidor Esteban Gómez de Acosta. Santiago de Querétaro: Gobierno del Estado de Querétaro, 1997.

Saldívar, Gabriel. Historia de la música en México: épocas precortesiana y colonial. Colab. Elisa Osorio Bolio. México: Secretaría de Educación Pública, 1934.

Sigüenza y Góngora, Carlos de. Glorias de Querétaro en la nueva Congregación eclesiástica de Maria Santísima de Guadalupe, con que se ilustra, y en el sumptuoso templo que dedicó a su obsequio Juan Caballero y Ocio... México: Viuda de Bernardo Calderón, 1680.

SPANG, Kurt. "Aproximación a la loa sacramental y palaciega: notas estructurales». Ignacio Arellano, Kurt Spang y M. Carmen Pinillos (eds.). Apuntes sobre la loa sacramental y cortesana: loas completas de Bances Candamo. Kassel: Reichenberger, 1994: 7-24.

Super, John C. La vida en Querétaro durante la Colonia, 1531-1810. México: Fondo de Cultura Económica, 1983.

Urzáiz Tortajada, Héctor. Catálogo de autores teatrales del siglo XVII. Madrid: Fundación Universitaria Española, 2002. 2 vols.

Zelá́ e Hidalgo, José María. Glorias de Querétaro, en la fundación y admirables progresos de la muy Ilustre y Venerable Congregación eclesiástica de presbiteros seculares de María Santísima de Guadalupe de México... que en otro tiempo escribió... Carlos de Sigüenza y Góngora... y que ahora escribe de nuevo el Br. D. Joseph María Zelaá e Hidalgo. México: Mariano José de Zuñiga y Ontiveros, 1803.

Zugasti, Miguel. «Teatro recuperado en Charcas: dos loas olvidadas de fray Juan de la Torre (OSA) a la entrada del virrey Diego Morcillo en Potosí, 1716». Ignacio Arellano y José Antonio Rodríguez Garrido (eds.). El teatro en la Hispanoamérica colonial. MadridFrankfurt: Iberoamericana-Vervuert, 2008: 295-322.

Zugasti, Miguel. «Teatro y fiesta en honor del nuevo virrey: dos loas al Conde de la Monclova en Puebla de los Ángeles (1686) y Lima (1689)». Miguel Zugasti, Ester Abreu y M. Mirtis Caser (eds.). El teatro barroco: textos y contextos. Vitória: Universidade Federal do Espírito Santo-AITENSO, 2014: 115-167. 
